\title{
Molecular Expression of a Recombinant Thermostable Bacterial Amylase from Geobacillus stearothermophilus SR74 Using Methanol-free Meyerozyma guilliermondii Strain SO Yeast System
}

\author{
Nurul S. M. Nasir, ${ }^{\mathrm{a}, \mathrm{b}}$ Chor T. Leow, ${ }^{\mathrm{a}, \mathrm{c}, \mathrm{d}}$ Siti N. H. Oslan, ${ }^{\mathrm{e}}$ Abu B. Salleh, ${ }^{\mathrm{a}}$ and \\ Siti N. Oslan ${ }^{\mathrm{a}, \mathrm{b}, \mathrm{d}, *}$
}

\begin{abstract}
a-Amylase, which was isolated from Geobacillus stearothermophilus SR74, has shown its potential to be used in industrial applications. However, its expression in the Pichia pastoris expression system with the alcohol oxidase 1 promoter $\left(\mathrm{P}_{\mathrm{AOX} 1}\right)$ requires high methanol consumption and is time-consuming. This study aimed to express SR74 $\alpha$-amylase in an alternative yeast system, using Meyerozyma guilliermondii strain SO, which was isolated from a spoiled orange (SO) under the regulation of a formaldehyde dehydrogenase promoter (PFLD). Qualitative screening showed that strain SO possessed a native amylase grown on YPD-starch plate at $30{ }^{\circ} \mathrm{C}$. The recombinant SR74 $\alpha$-amylase was further quantified and validated using the Western blot test. It was confirmed that SR74 $\alpha$ amylase was expressed by strain SO extracellularly with a size of $59 \mathrm{kDa}$. Optimization in a shake flask showed that the recombinant SR74 $\alpha$ amylase, which was regulated by $P_{F L D}$, was successfully produced (26 $\mathrm{U} / \mathrm{mL}$ ) without any external inducer in the YPT medium after $24 \mathrm{~h}$ of cultivation. In conclusion, strain SO was able to produce SR74 amylase without methanol in one-fifth the fermentation time of $P$. pastoris. Further optimization of the expression may be done to improve the yield, as this methanol-free host is still underexplored.
\end{abstract}

\begin{abstract}
Keywords: SR74 a-amylase; FLD promoter; Meyerozyma guilliermondii strain SO; Yeast; Pichia sp.; Amylase; Geobacillus stearothermophilus

Contact information: a: Enzyme and Microbial Technology Research Centre, Centre of Excellence, Universiti Putra Malaysia, 43400 UPM Serdang, Selangor, Malaysia; b: Department of Biochemistry, Faculty of Biotechnology and Biomolecular Sciences, Universiti Putra Malaysia, 43400 UPM Serdang, Selangor, Malaysia; c: Department of Cell and Molecular Biology, Faculty of Biotechnology and Biomolecular Sciences, Universiti Putra Malaysia, 43400 UPM Serdang, Selangor, Malaysia; d: Institute of Bioscience, Universiti Putra Malaysia, 43400 UPM Serdang, Selangor, Malaysia; e: Faculty of Bioengineering and Technology, Universiti Malaysia Kelantan, Jeli Campus, 17600 Jeli, Kelantan, Malaysia; *Corresponding author: snurbayaoslan@upm.edu.my
\end{abstract}

\section{INTRODUCTION}

$\alpha$-Amylase is one of the most used enzymes in the detergent, food, pharmaceutical, and industries, alongside lipase and protease. It belongs to the glycosyl hydrolase family that randomly cuts polysaccharides, such as starch or glycogen, by cleaving the internal $\alpha-$ 1,4-glycosidic bond to release simple sugar molecules such as maltoses or glucoses (Metin et al. 2010). In industrial practice, enzymes are used in extreme conditions particularly with respect to temperature (Prakash and Jaiswal 2010). Therefore, thermostability is one of main concerns for industrial amylase. Thermophilic microorganisms are preferred for the

Nasir et al. (2020). "Expressing recombinant amylase," BioResources 15(2), 3161-3172. 3161 
production of thermostable amylases (Kavanagh 2017). The properties offered by microbial thermostable $\alpha$-amylases have high commercial value, where the optimum temperature and $\mathrm{pH}$ range from $50{ }^{\circ} \mathrm{C}$ to $100^{\circ} \mathrm{C}$ and 5.0 to 10.5 , respectively (Lim et al. 2020).

The $\alpha$-amylase from a thermophile Geobacillus stearothermophilus SR74 has potential to be commercialized for industrial applications due to its thermostability (Gandhi et al. 2015). Hence, SR74 is required to be produced in large quantity. However, its production in wild-type G. stearothermophilus SR74 is too low (Kassaye 2019). Therefore, the Pichia pastoris expression system under an alcohol oxidase promoter ( $\left.\mathrm{P}_{\mathrm{AOX} 1}\right)$ regulation was used to maximize its production (Gandhi et al. 2015). Nonetheless, its production in this system required high methanol consumption and long fermentation time (Gandhi et al. 2015). Hence, the production cost of SR74 $\alpha$-amylase is expected to be expensive and uneconomical for industrial use.

$P$. pastoris (methylotrophic yeast) expression system has gained worldwide attention due to the presence of strong promoters, especially $\mathrm{P}_{\mathrm{AOX} 1}$, leading to high foreign protein production (Hartner and Glieder 2006). However, it also comes with a bottleneck. The $\mathrm{P}_{\mathrm{AOX} 1}$ promoter dependency on methanol is challenging in certain aspects. Methanol is a volatile chemical that easily evaporates. Hence, it is hard to monitor and maintain the methanol concentration, even at room temperature. Promoters, such as formaldehyde dehydrogenase $\left(\mathrm{P}_{\mathrm{FLD}}\right)$, that does not rely on methanol is considered as an alternative (Shen et al. 1998). The $\mathrm{P}_{\mathrm{FLD}}$ was reported to produce foreign protein in comparable yield as the $\mathrm{P}_{\mathrm{AOX} 1}$ in $P$. pastoris (Shen et al. 1998). It is a promising alternative as an $\mathrm{P}_{\mathrm{AOX} 1}$ (Cos et al. 2005).

Moreover, a newly developed expression host, $M$. guillermondii strain SO, has the potential to produce foreign protein at a faster rate than $P$. pastoris with minimal methanol induction (Oslan et al. 2015). P. pastoris requires $60 \mathrm{~h}$, whereas M. guillermondii strain $\mathrm{SO}$ requires $30 \mathrm{~h}$ to produce foreign protein at an optimum level (Oslan et al. 2015). To date, only $\mathrm{P}_{\mathrm{AOX} 1}$ and $\mathrm{P}_{\mathrm{FLD}}$ were found in this host. The $\mathrm{P}_{\mathrm{AOX} 1}$ is dependent on the methanol for induction purpose, whereas PFLD is able to respond to an inducer other than methanol, which is methylamine (Shen et al. 1998).

The objective of this study was to express SR74 $\alpha$-amylase in M. guilliermondii strain SO under the regulation of the PFLD.

\section{EXPERIMENTAL}

\section{Materials}

Strains and plasmids

Wild-type M. guilliermondii strain SO and Escherichia coli $\mathrm{DH} \alpha 5 / \mathrm{pJET} / \mathrm{SR} 74$ amylase harboring gene of interest were obtained from previous studies (Kassaye 2009; Oslan et al. 2012). P. pastoris KM71H, E. coli TOP10, and FLD promoter ( $\left.\mathrm{P}_{\mathrm{FLD}}\right)$ expression kit were purchased from Invitrogen (Carlsbad, CA, USA). M. guilliermondii strain SO and $P$. pastoris KM71H were maintained in YPD (yeast extract, peptone, and dextrose) broth, whereas E. coli TOP10 was maintained in LB (Luria-Bertani) broth. All of them were kept in glycerol stock at $-80{ }^{\circ} \mathrm{C}$ in a freezer. 


\section{Methods}

Screening of native amylase in $M$. guilliermondii strain $S O$

Preliminary screening of $\alpha$-amylase was completed using a method from a previous study (Effio et al. 2000). Wild-type $M$. guilliermondii strain SO was cultured on YPD agar containing $1 \%(\mathrm{w} / \mathrm{v})$ starch for 2 to 3 days. Lugol solution $(0.1 \%(\mathrm{w} / \mathrm{v})$ iodine and $1 \%(\mathrm{w} / \mathrm{v})$ potassium iodide) was flooded onto the plate for 5 to $10 \mathrm{~min}$. The protocol was completed at $30{ }^{\circ} \mathrm{C}$ without any induction.

\section{Cloning of SR74 $\alpha$-amylase into $\mathrm{P}_{\mathrm{FLD}}$}

SR74 $\alpha$-amylase gene was amplified using the primers flanked with PmlI and ApaI restriction sites (5'-3') (Fwd SR74 $\underline{P m l \mathrm{I}}$ : ATCACGTGTGCCGCACCGTTTAAC) and (Rvs SR74 ApaI: ATGGGCCCAGGCCATGCCACCAAC). Standard PCR amplification procedure was used with the annealing temperature $58{ }^{\circ} \mathrm{C}$. Next, the amplicon and FLD $\alpha$ plasmid were digested with PmlI and ApaI (ThermoFisher Scientific, USA) prior ligation. Then, the ligation mixture was transformed into $E$. coli TOP10 for propagation purposes according to protocols suggested by the EasySelect ${ }^{\mathrm{TM}}$ Pichia Expression Kit manual, Invitrogen (USA). Finally, it was transformed into $M$. guilliermondii strain SO. The cloning process was completed according to $\mathrm{FLD} \alpha$ manual (Invitrogen 2012). The transformant mixture was spread onto YPDS (w/v) (1\% yeast extract, $2 \%$ peptone, $2 \%$ dextrose, $2 \%$ agar, and $1 \mathrm{M}$ sorbitol) agar plates containing $100 \mu \mathrm{g} / \mathrm{mL} \mathrm{Zeocin}^{\mathrm{TM}}$.

\section{Quantitative screening expression of recombinant $S R 74 \alpha$-amylase}

Fourteen positive colonies from 60 colonies containing the SR74 $\alpha$-amylase gene were picked and subjected to expression screening. Minimum glycerol with ammonium sulphate medium (MGA) was used for biomass production before expression with an initial cell amount estimated by optical density at $600 \mathrm{~nm}$, i.e. $\mathrm{OD}_{600 \mathrm{~nm}}=4$. Culture in MGA medium was harvested and transferred into minimal methanol and ammonium sulphate medium (MMA) medium when the $\mathrm{OD}_{600 \mathrm{~nm}}$ was 4 in MMA medium. A total of $0.5 \%(\mathrm{v} / \mathrm{v})$ methanol was used for induction. Then, the cultures were harvested after $30 \mathrm{~h}$ at $3000 \times g$ at room temperature for $3 \mathrm{~min}$. The supernatant was assayed by 3,5-dinitrosalicylic acid assay for detection of $\alpha$-amylase activity.

\section{Qualitative screening of recombinant $\alpha$-amylase}

Preliminary screening of $\alpha$-amylase was performed according to a previous study (Effio et al. 2000). Colony 23 of M. guilliermondii strain SO containing recombinant plasmid, wild-type $\mathrm{SO}$, and $P$. pastoris $\mathrm{KM} 71 \mathrm{H}$ containing empty plasmid (negative control) were cultured on YPD (1\% yeast extract, $2 \%$ peptone, $2 \%$ dextrose, and $2 \%$ agar) agar containing $1 \%(\mathrm{w} / \mathrm{v})$ starch for 3 days. Then, Lugol solution $(0.1 \%(\mathrm{w} / \mathrm{v})$ iodine and $1 \%(\mathrm{w} / \mathrm{v})$ potassium iodide) was flooded onto the plate for 5 to $10 \mathrm{~min}$. This procedure was completed in triplicate at $30^{\circ} \mathrm{C}$ with methanol induction.

\section{Western blot analysis}

Western blot analysis was performed for confirmation of the expression of extracellular His-tag $\alpha$-amylase. It was completed according to the Western blot protocol (Novagen, USA). The sample (700 $\mu \mathrm{L}$ supernatant) was taken at $24 \mathrm{~h}$ in YPT medium and was concentrated using $700 \mu \mathrm{L}$ of $100 \%$ (w/v) trichloroacetic acid (TCA) (Koontz 2014). The concentrated supernatant was subjected to sodium dodecyl sulfate polyacrylamide gel electrophoresis (SDS-PAGE) (Bio-Rad, Philadelphia, PA, USA) for protein separation.

Nasir et al. (2020). "Expressing recombinant amylase," BioResources 15(2), 3161-3172. 3163 
Then, SDS-PAGE gel was used for blotting onto a nitrocellulose membrane with an applied current of $0.45 \mathrm{~mA}$ for $2 \mathrm{~h}$. Then, the prestained protein ladder well was cut from the membrane prior to the next steps and developing the colour. His-Tag Monoclonol Antibody and Goat-Anti-Mouse IgG HRP Conjugate (Novagen, USA) were used as primary and secondary antibodies, respectively.

\section{3,5-Dinitrosalicylic acid (DNS) assay}

The DNS assay was used to determine the reducing sugar (as a result of $\alpha$-amylase reaction) content in the medium (Bernfeld 1995). The assay was conducted based on a previous study (Gandhi et al. 2015). A $0.5 \mathrm{~mL}$ enzyme s and $0.5 \mathrm{~mL}$ starch $(1 \% \mathrm{w} / \mathrm{v})$ in $50 \mathrm{mM}$ phosphate buffer ( $\mathrm{pH} 7.0$ ) were mixed and allowed to react for $30 \mathrm{~min}$ at $60{ }^{\circ} \mathrm{C}$. Then, same amount of DNS reagent was added to each tube and incubated at $100{ }^{\circ} \mathrm{C}$ for $10 \mathrm{~min}$ in order to stop the reaction. Next, the tubes were allowed to cool to room temperature and the absorbance at $\mathrm{OD}_{540 \mathrm{~nm}}$ was taken. Reducing sugar was determined by comparing the absorbance at $\mathrm{OD}_{540 \mathrm{~nm}}$ of the assay solution with a maltose standard curve. Colour change from orange to red-brown $(540 \mathrm{~nm})$ indicated the presence of $\alpha$-amylase in the medium. The rate of $1 \%(\mathrm{w} / \mathrm{v})$ starch converted to $1 \mu \mathrm{M}$ maltose per minute was set to equal one unit of enzyme activity. The DNS assay was conducted in triplicate.

\section{Effect of different media on recombinant SR74 $\alpha$-amylase expression}

Different media were studied to maximize SR74 $\alpha$-amylase expression (Table 1). The MMAs, YPTM, and BMMY media were used for the optimization procedure. The MMG, YPTM, and BMMG were used for biomass accumulation. Then, $0.5 \%(\mathrm{v} / \mathrm{v})$ methanol was used to induce the enzyme expression in cell culture every $24 \mathrm{~h}$ in the MMAs, YPTM, and BMMY media. The composition of each medium is listed in Table 1. The cultures were harvested after $48 \mathrm{~h}$ at $3000 \times g$ at room temperature for $2 \mathrm{~min}$. The samples in the form of supernatants were assayed by the DNS assay method. The growth for each culture was also monitored at $\mathrm{OD}_{600 \mathrm{~nm}}$.

Table 1. Composition for Each Medium Used in Media Optimization

\begin{tabular}{|c|c|c|c|c|c|c|}
\hline Medium & MGAs & MMAs & BMGY & BMMY & YPTG & YPTM \\
\hline Yeast extract (w/v) & - & - & $2 \%$ & $2 \%$ & $1 \%$ & $1 \%$ \\
\hline Peptone (w/v) & - & - & $2 \%$ & $2 \%$ & $2 \%$ & $2 \%$ \\
\hline Tryptic soy broth (w/v) & - & - & - & - & $0.2 \%$ & $0.2 \%$ \\
\hline Yeast nitrogen base (w/v) & $1.34 \%$ & $1.34 \%$ & - & - & - & - \\
\hline Biotin $(w / v)$ & $4 \times 10^{-5 \%}$ & $4 \times 10^{-5 \%}$ & - & - & $4 \times 10^{-5 \%}$ & - \\
\hline Glycerol (v/v) & $1 \%$ & & $1 \%$ & - & $1 \%$ & - \\
\hline Methanol (v/v) & - & $0.5 \%$ & & $0.5 \%$ & & $0.5 \%$ \\
\hline $\begin{array}{c}\text { Potassium phosphate } \\
\text { buffer }\end{array}$ & _ & & $\begin{array}{c}100 \mathrm{mM}, \\
\mathrm{pH} 6\end{array}$ & $\begin{array}{c}100 \mathrm{mM}, \\
\mathrm{pH} 6\end{array}$ & & \\
\hline
\end{tabular}

MGAs: Minimal glycerol and ammonium sulphate medium; MMAs: Minimal methanol and ammonium sulphate medium; BMGY: Buffered glycerol complex medium; BMMY: Buffered methanol complex medium: YPTG: Yeast extract, peptone, tryptic soy broth, and biotin and glycerol medium; and YPTM: Yeast extract, peptone, tryptic soy broth, and biotin and methanol medium

\section{Effect of different inducers}

Different inducers were studied to optimize the $\alpha$-amylase yield. Different inducers, such as $0.5 \%(\mathrm{v} / \mathrm{v})$ methanol, $0.5 \%(\mathrm{v} / \mathrm{v})$ methanol, and $0.25 \%(\mathrm{v} / \mathrm{v})$ methylamine, and 
$0.25 \%(\mathrm{v} / \mathrm{v})$ methylamine, were used. The YPTG medium was used in the inducer optimizations because it was able to express the highest SR74 $\alpha$-amylase. The cultures were harvested at $48 \mathrm{~h}$. The supernatants were assayed using the DNS assay method. The growth reading at $600 \mathrm{~nm}$ was examined for every culture.

\section{Time course study}

Time course study was conducted to determine the time point at which the expression was the highest. Colony 23 of recombinant $M$. guilliermondii strain SO (pFLD $\alpha=/ \alpha$-amylase), P. pastoris $\mathrm{KM} 71 \mathrm{H}$ (pFLD $\alpha / \alpha$-amylase), and $M$. guilliermondii strain $\mathrm{SO}(\mathrm{pFLD} \alpha)$ were grown under the same protocol as described earlier. Amylase activity and growth at $\mathrm{OD}_{600 \mathrm{~nm}}$ were monitored at $12 \mathrm{~h}$ intervals for $60 \mathrm{~h}$.

\section{RESULTS AND DISCUSSION}

\section{Quantitative and Qualitative Screening of $\alpha$-Amylase Expression}

Quantitative screening was conducted on 14 colonies. They were chosen based on the brightness of the band from colony polymerase chain reaction (PCR). Among the 14 colonies examined, colony number 23 showed the highest amylase activity. Hence, it was selected for the next optimization procedure. Figure 1 shows amylase screening agar plate for recombinant $M$. guilliermondii strain SO of colony 23, wild-type $M$. guilliermondii strain SO, and wild-type $P$. pastoris $\mathrm{KM} 71 \mathrm{H}$ under methanol induction. Based on Fig. 1(B), wild-type SO had lower amylase activity than recombinant SO on Fig. 1(A). The larger non-blue colour (halo-zone) region observed with recombinant SO was due to the total amylase activity from both native and recombinant amylases. P. pastoris on Fig. 1(C) served as a negative control for the screening plate procedure. No amylase activity was observed from $P$. pastoris.
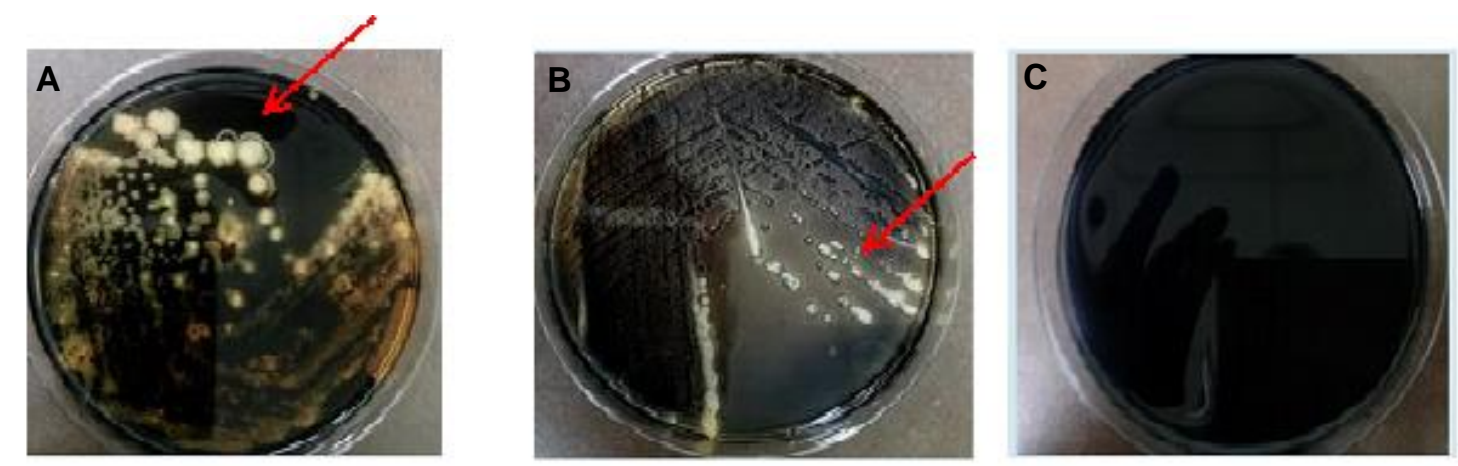

Fig. 1. Amylase plate screening of respective yeast species: $(A)$ recombinant $M$. guilliermondii strain SO; (B) wild-type M. guilliermondii strain SO; and (C) wild-type $P$. pastoris $\mathrm{KM} 71 \mathrm{H}$ with methanol induction (negative control). The screening plates were performed at $30^{\circ} \mathrm{C}$ and were induced with methanol. The non-blue colour region/halo zone indicated the presence of amylase. The arrow shows a positive single colony. The recombinant $M$. guilliermondii strain SO had a larger halo zone area than the wild-type M. guilliermondii strain SO.

\section{Western Blot Analysis}

Western blot was used to identify the protein of interest in a protein complex. Western blot has been used widely for the detection of the protein of interest in methylotrophic yeast, especially for P. pastoris (Linder et al. 1997; Gandier and Master

Nasir et al. (2020). "Expressing recombinant amylase," BioResources 15(2), 3161-3172. 3165 
2018). Hence, Western blot analysis was chosen to validate the expression of extracellular His-tag SR74 $\alpha$-amylase in the supernatant. Trichloroacteic acid (TCA) precipitation method was chosen to concentrate the recombinant $\alpha$-amylase in the supernatant. The TCA precipitation method was chosen to concentrate the SR74 $\alpha$-amylase due to its simplicity and simple and reliable process. His-tagged SR74 $\alpha$-amylase was identified based on the dark purple colour that formed on the nitrocellulose membrane. As displayed in Fig. 2, the purple colour band was developed at a protein size in the range of 48 to $63 \mathrm{kDa}$, which corresponded to the size of the SR74 $\alpha$-amylase (59 kDa) on L2. Thus, it was confirmed that extracellular SR74 $\alpha$-amylase was successfully expressed and secreted into the culture medium. $P$. pastoris has the ability to secrete the foreign proteins using both native host signal sequence and $\alpha$-factor secretion signal from $S$. cerevisiae (which was presence in Pichia expression vectors). Paifer et al. (1994) reported that the secretion thermostable of bacterial $\alpha$-amylase was higher in P. pastoris when using the $\alpha$-factor secretion signal from $S$. cerevisiae than when the native host signal sequence was used. This feature was also demonstrated by other foreign protein expression in P. pastoris (Latiffi et al. 2013). It was confirmed that $P$. pastoris could be used to secrete foreign proteins using both signal sequences.

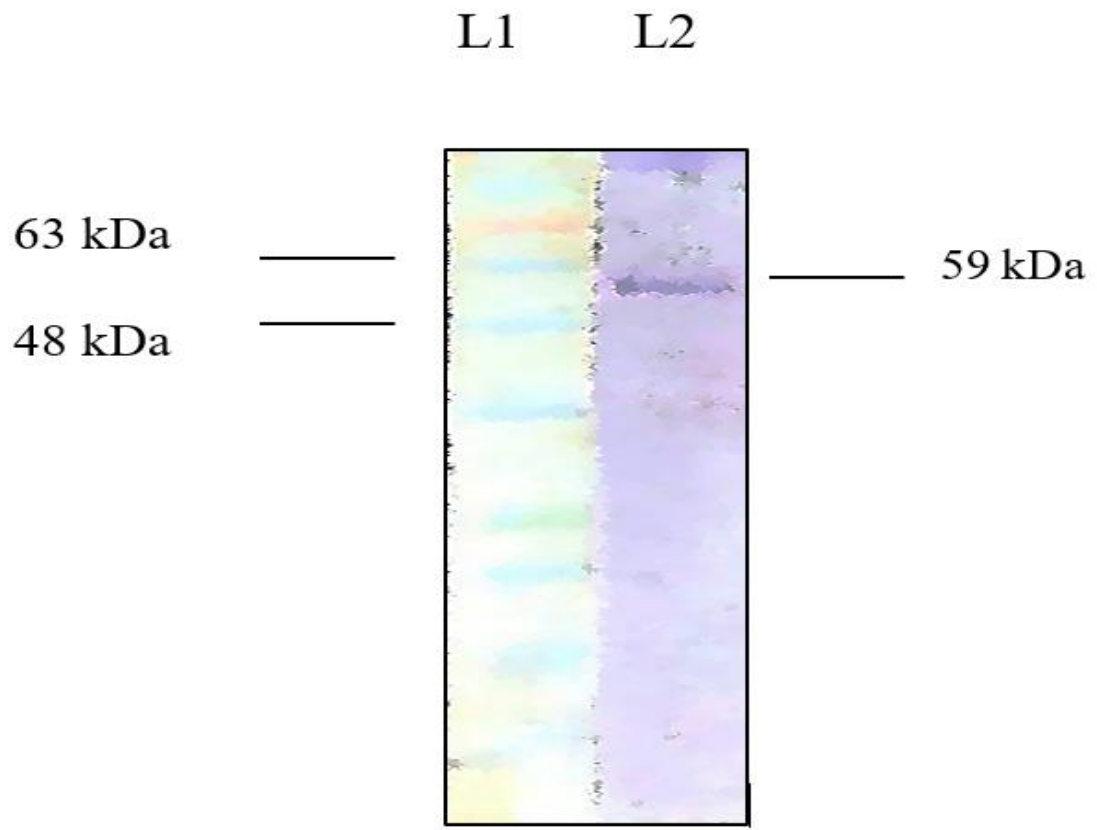

Fig. 2. Western blot analysis extracellular SR74 $\alpha$-amylase: L1: SMOBio tri-colour pre-stained protein ladder pre-stained protein marker; and L2: crude extract of $\alpha$-amylase. The size of the amylase was approximately $59 \mathrm{kDa}$. Colour of the membrane for $\mathrm{L} 1$ and $\mathrm{L} 2$ was different due to the multiple washing and staining steps used to detect the present of His-tagged protein where these steps were not applied to the prestained protein marker.

\section{Effect of Different Media on Recombinant $\alpha$-Amylase Production}

Media optimization is one of the basic elements in the optimization procedure. It had to be conducted prior to large-scale fermentation. According to the Invitrogen manual (Invitrogen 2012) and a previous study (Gandhi et al. 2015), three types of media were chosen in media optimization. Fig. 3 displays the graph of the effect of different media on recombinant $\alpha$-amylase production and cell growth. The YPTM produced the highest cell density and $\alpha$-amylase expression than the others. The YPTM is a complex medium rich 
in trace elements, amino acids, peptides, vitamins, and carbon, as well as an energy source (Tao et al. 1999). Cell density increased rapidly, and expression of genes was elevated while the biosynthesis pathway was turned off in the rich media (Tao et al. 1999; Kim and Kim 2017). A similar trend was observed in the YPTM medium. Cell growth is connected to protein production (Oslan et al. 2015). An increase in cell density led to an increase in protein production. Therefore, YPTM was the best medium for the expression of SR74 $\alpha$ amylase. From the finding, MMA did not promote high cell density of yeast growth as well as the recombinant SR74 $\alpha$-amylase expression level in strain SO. Because MMA is a minimal medium, only expression of housekeeping genes involving in biosynthetic pathways are up-regulated to build the building blocks from single energy and carbon source in response to stress (Tao et al. 1999) and survive (Kim and Kim 2017). There was also protein instability caused by extracellular proteases. It is essential to supply casamino acid in the minimal medium for the prevention of protein degradation (Clare et al. 1991). In contrast, BMMY did increase the cell density but did not promote $\alpha$-amylase expression. Generally, there should be a correlation between cell density and gene expression. With respect to the BMMY medium, the $\mathrm{pH}$ might be the factor that led to the low expression of amylase even though the cell density was high. At a pH 6.0, the medium is optimum for the production of the protein using BMMY medium (Clare et al. 1991; Maleki et al. 2010). Hence, it was used in this study. However, $\mathrm{pH} 6.0$ might not be a suitable $\mathrm{pH}$ for extracellular $\alpha$-amylase, which led to the low amylase activity. Environmental $\mathrm{pH}$ is one the factors that affects protein structure (Monahan et al. 1995). The appropriate protein structure is crucial for the protein to function (Sharma 2013). Thus, $\mathrm{pH}$ optimization was crucial for SR74 $\alpha$-amylase production in the BMMY medium.

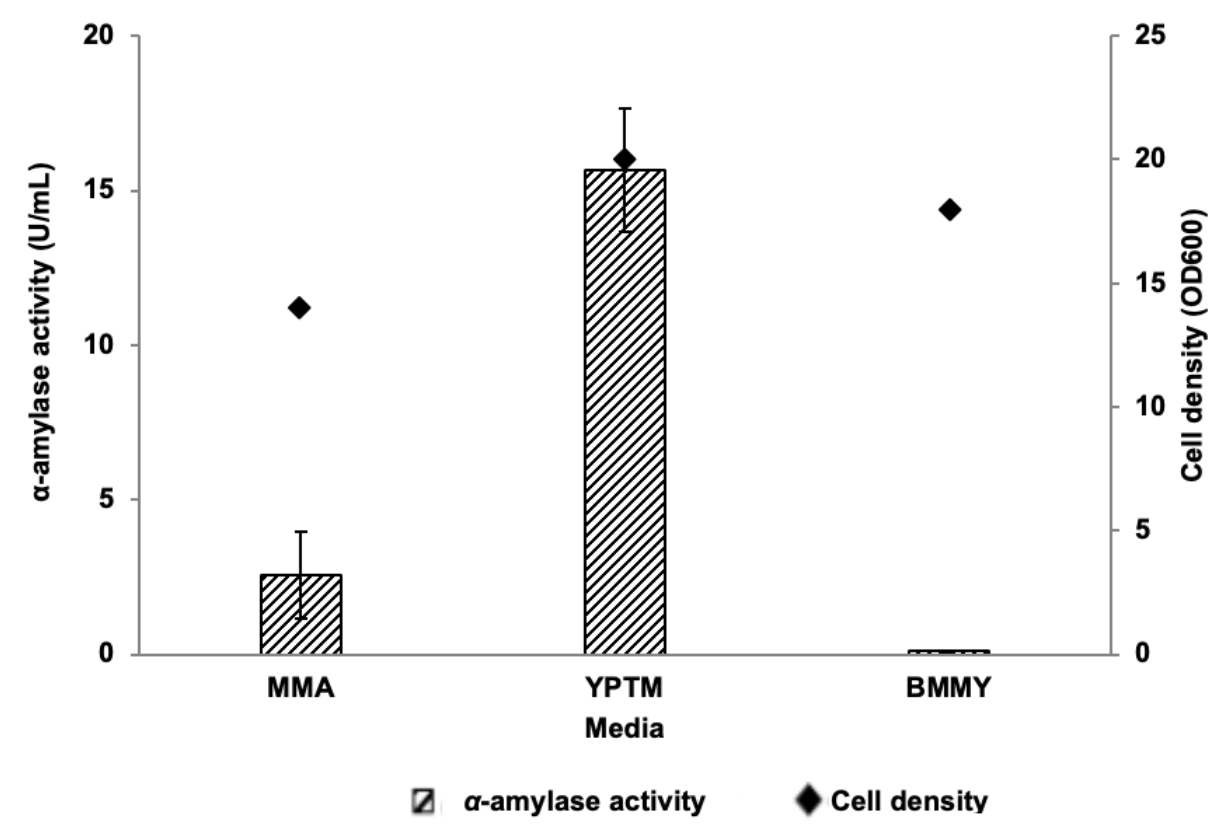

Fig. 3. Effect of different media on $\alpha$-amylase production and cell density of recombinant $M$. guilliermondii strain SO. The reading was taken at $48 \mathrm{~h}$ with $0.5 \%(\mathrm{v} / \mathrm{v})$ methanol induction. The initial biomass was in the range of $\mathrm{OD}_{600 \mathrm{~nm}}$ of 14 to 16 . MMA: minimal methanol medium; YPTM: yeast extract, peptone, tryptic soy broth, and biotin and methanol medium; and BMMY: buffered minimal methanol yeast extract. All data are presented as mean of \pm standard deviation of triplicates. The bar chart represents $\alpha$-amylase activity and the rhombus symbol indicates cell density. 


\section{Effects of Different Inducers}

The $\mathrm{P}_{\mathrm{FLD}}$ is the alternative to the $\mathrm{P}_{\mathrm{AOX} 1}$. Both promoters are strongly inducible and able to produce high foreign protein production. The ability of the $\mathrm{P}_{\mathrm{FLD}}$ to respond to methylamine makes it an attractive promoter over the $\mathrm{P}_{\mathrm{AOX} 1}$. Methylamine is less expensive and easier to handle than methanol. The $\mathrm{P}_{\mathrm{FLD}}$ can be induced by methanol and/or methylamine in $P$. pastoris. Methylamine was the best inducer for foreign protein production in P. pastoris (Shen et al. 1998). However, the best inducer for the $P_{F L D}$ in $M$. guilliermondii strain SO is still unknown. Hence, it was essential to identify the best inducer for the promoter before proceeding to large-scale fermentation.

Figure 4 shows the effect of different inducers on $\alpha$-amylase production and cell growth. Initially, the culture with no inducer was a negative control for this optimization procedure. It was unexpected that culture with no inducer was able to express the highest amylase activity than culture with inducer(s). This is the first study to date that reports the ability of $\mathrm{P}_{\mathrm{FLD}}$ to produce foreign protein without any external inducer. Its expression was the highest $(23 \mathrm{U} / \mathrm{mL})$. The $\mathrm{P}_{\mathrm{AOX} 1}$ in a similar host also was able to express foreign protein without methanol induction, but at low yield. A mere $2 \mathrm{U} / \mathrm{mL}$ lipase was produced after optimization using response surface methodology (RSM) (Abu et al. 2017). The study reported by Abu et al. (2017) had used M. guilliermondii strain SO to express recombinant T1 lipase and had shown similar feature to this study where the methanol inducible promoters ( $\mathrm{P}_{\mathrm{AOX} 1}$ and $\left.\mathrm{P}_{\mathrm{FLD}}\right)$ could express the recombinant proteins without the present of methanol. But, no activity of $\mathrm{P}_{\mathrm{FLD}}$ was observed with $0 \%$ methanol induction (without inducer) in Pichia methanolica. Additionally, studies were also conducted with P. pastoris, Hansenula polymorpha, and Candida boidinii, where the studies' focus was more on the comparison between different inducers than with or without inducer. Comparison with and without induction between $M$. guilliermondii strain SO and well-known expression hosts could not be performed. To date, the expression of recombinant proteins with the uninduced inducible promoters were only present in M. guilliermondii strain SO.

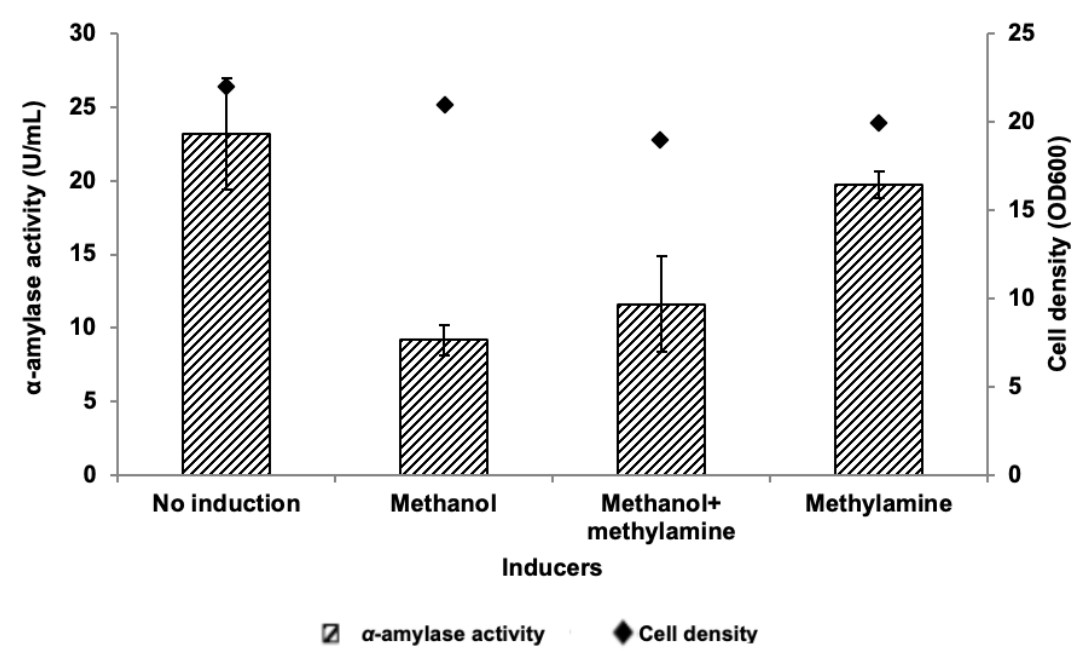

Fig. 4. Effect of different inducers on $\alpha$-amylase production and cell growth. The reading was conducted at $48 \mathrm{~h}$ starting with initial biomass of $\mathrm{OD}_{600 \mathrm{~nm}} 18$ to 20. Concentration of inducers was: methanol $0.5 \%(\mathrm{v} / \mathrm{v})$ and methylamine $0.25 \%(\mathrm{v} / \mathrm{v})$. Culture with no inducer produced the highest $\alpha$-amylase expression compared to methanol, methanol and methylamine, and methylamine. All data are presented as mean of \pm standard deviation of triplicates. The bar chart represents $\alpha$ amylase activity and the rhombus shapes indicate cell density. 


\section{Time Course Study}

A time course study was conducted to determine at which particular time the production of $\alpha$-amylase was the highest. Figure 5 shows the growth study and expression of $\alpha$-amylase at optimum conditions. Generally, the growth of microorganisms consists of four main stages: lag phase, log phase, stationary phase, and death phase. With respect to M. guilliermondii strain SO, 0 to $24 \mathrm{~h}$ was the $\log$ phase, 24 to $36 \mathrm{~h}$ was the stationary phase, and 36 to $60 \mathrm{~h}$ was the death phase (lag phase is where this yeast was grown in the YPTG medium for $24 \mathrm{~h}$ ). The expression level of $\alpha$-amylase in $M$. guilliermondii strain SO seemed to be related to the growth phase. $\alpha$-Amylase expression increased as the cell density increased during the log phase. The log phase is a phase where all cellular constituents are synthesized at a constant rate (Monod 1949). Protein synthesis mostly occurs at this stage (Monod 1949).

The expression was the highest $(26 \mathrm{U} / \mathrm{mL})$ at the beginning of the stationary phase. Moreover, the highest production of foreign protein under different promoter $\left(\mathrm{P}_{\mathrm{AOX} 1}\right)$ was also at the beginning of the stationary phase (Oslan et al. 2015). During the stationary phase, the cell growth starts to slow down until it is in balance with cell deaths (Albertson et al. 1990; Kolter et al. 1993). The slowing of cell growth is due to the excretion of the toxic compounds into the medium, depletion of nutrients and oxygen, and accumulation of carbon dioxide. These factors are intensified during the death phase. During the death phase, cell growth decreases drastically. The declining of viable cells reduces protein expression (Albertson et al. 1990). This explains the expression level of $\alpha$-amylase that started to drop after $36 \mathrm{~h}$. Wild-type $M$. guilliermondii strain SO infrequently showed any amylase activity. As a conclusion, $\alpha$-amylase activity was solely from recombinant SR74 $\alpha$-amylase and native/inherent amylase was a non-thermostable (DNS assay was performed at $65^{\circ} \mathrm{C}$ ) extracellular amylase.

This newly developed expression system using M. guilliermondii strain $\mathrm{SO}$ as a host and $\mathrm{P}_{\mathrm{FLD}}$ as a chosen promoter was able to produce a comparable yield of $\alpha$-amylase to the established $P$. pastoris expression system at one-fifth the fermentation time grown without any external inducer. Specifically, the newly developed system was able to produce $1.08 \mathrm{U} / \mathrm{mL}$ of $\alpha$-amylase per hour. In contrast, $P$. pastoris expression system could only produce $0.24 \mathrm{U} / \mathrm{mL}$ of $\alpha$-amylase per hour. There was a 16-fold increase in terms of production rate in this newly developed expression system. Therefore, this newly developed system is beneficial for the mass production of SR74 $\alpha$-amylase for its commercialization purposes in industrial applications.

\section{CONCLUSIONS}

1. Recombinant SR74 $\alpha$-amylase was expressed extracellularly in a new expression system using the yeast expression host of recombinant $M$. guilliermondii strain $\mathrm{SO} / \mathrm{pFLD} \alpha / \alpha$-amylase.

2. M. guilliermondii strain SO isolated from spoiled orange was shown to produce $\alpha$ amylase at a comparably higher yield than the commercial $P$. pastoris expression system without any external inducer (methanol and/or methylamine) at a much shorter fermentation time. 
3. The production cost of $\alpha$-amylase from strain SO is expected to be appreciably lower due to its shorter fermentation time and without any need for inducers. Thus, a new expression system with higher production rate of SR74 $\alpha$-amylase was developed.

4. SR74 $\alpha$-amylase has a higher chance for application in food, feed, and pharmaceutical industries because its optimum production does not require any chemical/inducer, with high potential for toxicity.

\section{ACKNOWLEDGMENTS}

This study was fully funded by Universiti Putra Malaysia under the Putra Grant Putra Graduate Initiative that was awarded to the last author (Grant No. GPIPS/2017/9516700). The authors would also like to thank the members of the Enzyme and Microbial Researach Center (EMTech) for the support and guidance in the completion of this study.

\section{REFERENCES CITED}

Abu, M. L., Nooh, H. M., Oslan, S. N., and Salleh, A. B. (2017). "Optimization of physical conditions for the production of thermostable T1 lipase in Pichia guilliermondii strain SO using response surface methodology," BMC Biotechnology 17, Article Number 78. DOI: 10.1186/s12896-017-0397-7

Albertson, N. H., Nystrom, T., and Kjelleberg, S. (1990). "Macromolecular synthesis during recovery of the marine Vibrio sp. S14 from starvation," Journal of General Microbiology 136(11), 2201-2207. DOI: 10.1099/00221287-136-11-2201

Bernfeld, P. (1995). "Amylase $\alpha$ and $\beta$," Methods in Enzymology 1, 149-158. DOI: 10.1016/0076-6879(55)01021-5

Clare, J. J., Romanes, M. A., Rayment, F. B., Rowedder, J. E., Smith, M. A., Payne, M. M., Sreekrishna, K., and Henwood, C. A. (1991). "Production of mouse epidermal growth factor in yeast: High-level secretion using Pichia pastoris strains containing multiple gene copies," Gene 105(2), 205-212. DOI: 10.1016/0378-1119(91)90152-2

Cos, O., Resina, D., Ferrer, P., Montesinos, J. L., and Valero, F. (2005). "Heterologous production of Rhizopus oryzae lipase in Pichia pastoris using the alcohol oxidase and formaldehyde dehydrogenase promoters in batch and fed-batch cultures," Biochemical Engineering Journal 26(2-3), 86-94. DOI: 10.1016/j.bej.2005.04.005

Effio, P. C., Silva, E. F., and Pueyo, M. T. (2000). "A simple and rapid method for screening amylolytic bacteria," Biochemical Education 28(1), 47-49. DOI: 10.1111/j.1539-3429.2000.tb00014.xl

Gandhi, S., Salleh, A. B., Raja Abd Rahman, R. N. Z., Chor, L. T., and Oslan, S. N. (2015). "Expression and characterization of Geobacillus stearothermophilus SR74 recombinant $\alpha$-amylase in Pichia pastoris," BioMed Research International 2015, Article ID 529059. DOI: 10.1155/2015/529059

Gandier, J. A., and Master, E. R. (2018). "Pichia pastoris is a suitable host for the heterologous expression of predicted class I and class II hydrophobins for discovery, study, and application in biotechnology," Microorganisms 6(1), Article Number 3. DOI: 10.3390/microorganisms6010003 
Hartner, F. S., and Glieder, A. (2006). "Regulation of methanol utilisation pathway genes in yeasts," Microbial Cell Factories 5, Article Number 39. DOI: 10.1186/1475-28595-39

Invitrogen (2012). pFLD and pFLD : Pichia pastoris Expression Vectors for Inducible Expression with Memethylamine and Selection on Zeocin ${ }^{\mathrm{TM}}$, Invitrogen, Carlsbad, CA, (https://www.thermofisher.com/document-connect/documentconnect.html?url=https $\% 3 \mathrm{~A} \% 2 \mathrm{~F} \% 2$ Fassets.thermofisher.com\%2FTFSAssets\%2FLSG\%2Fmanuals\%2Fpfld_man.pdf\&title=cEZMRA==), Accessed 28 Jan 2017.

Kassaye, E. K. (2009). Molecular Cloning and Expression of a Thermostable $\alpha$-amylase from Geobacillus sp., Master's Thesis, Universiti Putra Malaysia, Serdang, Selangor, Malaysia.

Kavanagh, K. (2017). Fungi: Biology and Applications, $3^{\text {rd }}$ Ed., Wiley-Blackwell, Hoboken, NJ, USA. DOI: 10.1002/9781119374312

Kim, J., and Kim, K. H. (2017). "Effects of minimal media vs. complex media on the metabolite profiles of Escherichia coli and Saccharomyces cerevisiae," Process Biochemistry 57, 64-71. DOI: 10.1016/j.procbio.2017.04.003

Kolter, R., Siegele, D. A., and Tormo, A. (1993). "The stationary phase of the bacterial life cycle," Annual Review of Microbiology 47, 855-874. DOI: 10.1146/annurev.mi.47.100193.004231

Koontz, L. (2014). "TCA precipitation," in: Laboratory Methods in Enzymology: Protein Part C, Methods in Enzymology, Academic Press, Cambridge, MA, USA, pp. 3-10. DOI: 10.1016/B978-0-12-420119-4.00001-X

Latiffi, A. A., Salleh, A. B., Rahman, R. N. Z. R. A., Oslan, S. N., and Basri, M. (2013). "Secretory expression of thermostable alkaline protease from Bacillus stearothermophilus FI by using native signal peptide and $\alpha$-factor secretion signal in Pichia pastoris, ” Genes \& Genetic Systems, 88(2), 85-91. DOI:10.1266/ggs.88.85

Lim, S. J., Oslan, S. H., and Oslan, S. N. (2020). "Purification and characterisation of thermostable $\alpha$-amylases from microbial sources," BioResources, 15(1), 2005-2029. DOI: 10.15376/biores.15.1. Lim

Linder, S., Schliwa, M., and Kube-Granderath, E. (1997). "Expression of Reticulomyxa filosa tubulins in Pichia pastoris: Regulation of tubulin pools," FEBS Letters 417(1), 33-37. DOI: 10.1016/s0014-5793(97)01250-7

Maleki, A., Roohvand, F., Tajerzadeh, H., Khanahmad, H., Nobari, M. B., Beiruti, A., and Najafabadi, A. R. (2010). "High expression of methylotrophic yeast-derived recombinant human erythropoietin in a $\mathrm{pH}$-controlled batch system," Avicenna Journal of Medical Biotechnology 2(4), 197-206.

Metin, K., Koç, Ö. Z., Ateşlier, B. B., and Bıyık, H. H. (2010). "Purification and characterization of $\alpha$-amylase produced by Penicillium citrinum HBF62," African Journal of Biotechnology 9(45), 7692-7701. DOI: 10.5897/AJB09.1687

Monahan, F. J., German, J. B., and Kinsella, J. E. (1995). "Effect of pH and temperature on protein unfolding and thiol/disulfide interchange reactions during heat-induced gelation of whey proteins," Journal of Agricultural and Food Chemistry 43(1), 46-52. DOI: $10.1021 / \mathrm{jf00049a010}$

Monod, J. (1949). "The growth curve of bacterial culture," Annual Review of Microbiology 3, 371-394. DOI: 10.1146/annurev.mi.03.100149.002103

Oslan, S. N., Salleh, A. B., Rahman, R. N. Z. R. A., Basri, M., and Chor, A. L. T. (2012). "Locally isolated yeasts from Malaysia: Identification, phylogenetic study and 
characterization," Acta Biochimica Polonica 59(2), 225-229. DOI:

10.18388/abp.2012_2142

Oslan, S. N., Salleh, A. B., Rahman, R. N. Z. R. A., Leow, T. C., Sukamat, H., and Basri, M. (2015). "A newly isolated yeast as an expression host for recombinant lipase," Cellular and Molecular Biology Letters 20(2), 279-293. DOI: 10.1515/cmble-20150015

Paifer, E., Margolles, E., Cremata, J., Montesino, R., Herrera, L., and Delgado, J. M. (1994). "Efficient expression and secretion of recombinant alpha amylase in Pichia pastoris using two different signal sequences," Yeast 10(11), 1415-1419. DOI:10.1002/yea.320101104

Prakash, O., and Jaiswal, N. (2010). “ $\alpha$-Amylase: An ideal representative of thermostable enzymes," Applied Biochemistry and Biotechnology 160(8), 2401-2414. DOI: 10.1007/s 12010-010-9073-2

Sharma, R. (2013). "Biochemical mechanisms of fatty liver and bioactive foods: Fatty liver, diagnosis, nutrition therapy," in: Bioactive Food as Dietary Interventions for Liver and Gastrointestinal Disease, R. R. Watson, and V. R. Preedy (eds.), Academic Press, San Diego, CA, pp. 623-625. DOI: 10.1016/B978-0-12-397154-8.00181-0

Shen, S., Sulter, G., Jeffries, T. W., and Cregg, J. M. (1998). "A strong nitrogen sourceregulated promoter for controlled expression of foreign genes in the yeast Pichia pastoris," Gene 216(1), 93-102. DOI: 10.1016/s0378-1119(98)00315-1

Tao, H., Bausch, C., Richmond, C., Blattner, F. R., and Conway, T. (1999). "Functional genomics: Expression analysis of Escherichia coli growing on minimal and rich media," Journal of Bacteriology 181(20), 6425-6440.

Article submitted: September 3, 2019; Peer review competed: March 8, 2020; Revised version received: March 10, 2020; Accepted: March 15, 2020; Published: March 18, 2020.

DOI: $10.15376 /$ biores.15.2.3161-3172 